\title{
A QUESTÃO DA VEGETAÇÃO NO AMBIENTE URBANIZADO
}

GALLO, Zildo. Professor e pesquisador do Programa de Mestrado em Desenvolvimento Regional e Meio Ambiente do Centro Universitário de Araraquara - Uniara.

SOSSAE, Flávia Cristina. Pesquisadora do Programa de Mestrado em Desenvolvimento Regional e Meio Ambiente e professora do curso de Ciências Biológicas do Centro Universitário de Araraquara - Uniara.

E-mail: f.sossae@terra.com.br.

\section{RESUMo}

O crescimento populacional e a expansão urbana provocam o desenraizamento cultural dos migrantes rurais, $\mathrm{o}$ aumento da pobreza, problemas ecológicos causados pela impermeabilização do solo e poluições atmosférica, hídrica, sonora e visual, além da redução da cobertura vegetal. Arápida expansão da Região Metropolitana de São Paulo e da Região Metropolitana da Campinas gerou impactos socioambientais, que foram agravados pela visão inadequada das questões ambientais por conta dos gestores urbanos. A finalidade deste trabalho foi analisar a urbanização sob os aspectos ambientais e sociais do crescimento econômico, possibilitando sugerir ações para evitar a ruptura cultural da população através do planejamento urbano direcionado para a ocupação e uso racional do solo, bem como a preocupação com a arborização das ruas e criação de áreas verdes como ferramenta para a educação ambiental contribuir no exercício da cidadania na transformação da sociedade atual em uma sustentável.

Palavras-chave: Urbanização; Desenvolvimento econômico; Arborização; Sustentabilidade.

\begin{abstract}
Population growth and urban expansion have provoked the cultural rootlessness of rural migrants, poverty increase, ecological problems caused by the impermeability of the soil and by atmosphere, water and sound pollution, besides the reduction of the vegetable covering. The rapid expansion of the Metropolitan Region of São Paulo and Campinas has generated socio-environmental impacts, which have been worsened by an inappropriate vision of the environmental issues by the urban managers. The aim of this work has been to analyze the urbanization taking into account the environmental and social aspects of the economic growth, making it possible to suggest actions to avoid the cultural rupture of the population, by means of an urban planning directed to the soil occupation and to the rational use of the soil, as well as the worry with tree planting in the streets and the creation of green areas as a tool for environmental education to contribute to the practicing of citizenship for the transformation of our society in a sustainable one.
\end{abstract}

KEYWORDS: Urbanization; Economical development; Tree planting; Sustainability. 


\section{INTRODUÇÃo}

Urbanização e meio ambiente: crises sociais e ambientais

Conforme o Relatório Brundtland (Nosso Futuro Comum), "poucos governos das cidades do mundo em desenvolvimento, cujas populações crescem em ritmo acelerado, dispõem de poderes, recursos e pessoal treinado para fornece-lhes as terras, os serviços e sistemas adequados a condições humanas de vida: água potável, saneamento, escolas e transportes" (CMMAD, p. 18-19).

O resultado disso é a proliferação de assentamentos ilegais, crescimento das favelas, ausência de serviços urbanos - como água tratada, coleta e transporte de esgotos e resíduos sólidos, entre outros. Percebe-se um claro descompasso, um gigantesco hiato temporal, entre o surgimento das necessidades e a capacitação do poder público para atendê-las.

Ocorre que a urbanização é um fato irreversível em todo o planeta. É importante lembrar aqui que, no início do século XX, apenas $10 \%$ da população da Terra habitava os centros urbanos. Já no final do século, os habitantes urbanos representavam cerca de $50 \%$ da população total. No século XXI, o processo continua (SIRKIS, 2005).

No Brasil, conforme informações do IBGE, o fenômeno se repete. Em 1950, por exemplo, 36\% da população brasileira estava nas áreas urbanas. Em 2000, a participação da população urbana sobre a total girava em torno de $81 \%$. Trata-se de uma explosão urbana, pois se observa um salto de cerca de 19 milhões para cerca de 138 milhões (ver Tabela 1).

Tabela 1 - Evolução da população no Brasil (em milhões).

\begin{tabular}{|r|r|r|r|r}
\hline \multicolumn{1}{c|}{ Ano } & \multicolumn{1}{|c|}{ Total } & \multicolumn{1}{|c|}{ Urbana } & \multicolumn{1}{c|}{ Rural } & Urbanização (\%) \\
\hline $\mathbf{1 9 5 0}$ & 51,9 & 18,8 & 33,1 & 36,2 \\
\hline $\mathbf{2 0 0 0}$ & 169,5 & 137,7 & 31,8 & 81,2 \\
\hline
\end{tabular}

Fonte: IBGE (vários anos).

Na verdade, o que se observa na segunda metade do século XX é que, apesar do crescimento da população total, de 51,9 milhões para 169,5 milhões, a população rural também decresceu em termos absolutos, de 33,1 milhões para 31,8 milhões. Isso ajuda a explicar o surgimento de megacidades no Brasil, como a cidade de São Paulo, por exemplo, que conta com mais de 10 milhões de habitantes e está entre as cidades do mundo.

Todo crescimento populacional e toda expansão urbana são impactantes ao meio ambiente. Contudo, podem ser mais ou menos impactantes, dependendo da sua dimensão, do tempo em que ocorre e, também, da forma como ocorre.

As cidades muito grandes, em função do volume de serviços necessários ao atendimento de suas populações, nem sempre disponíveis, tendem a enfrentar mais problemas que os centros urbanos menores. Uma expansão populacional mais lenta permite uma readaptação paulatina, mais adequada, das condições ambientais. O crescimento não planejado, "ao acaso", muitas vezes a serviço da mera especulação imobiliária, pode criar sérios problemas ecológicos causados pela impermeabilização do solo e poluições atmosférica, hídrica, sonora e visual, além da redução da cobertura vegetal, dificultando o trabalho de minimização dos impactos pelo poder público.

A situação das cidades pode ser agravada mais ainda, caso o crescimento populacional se faça acompanhar pela concentração de renda e do aumento da pobreza. É o caso do Brasil e do Estado de São Paulo. 
O Estado de São Paulo, com destaque para a Região Metropolitana de São Paulo - RMSP, a partir da sua industrialização, transformou-se num polo de atração populacional, como no caso das populações rurais da Região Nordeste. Nem todos os migrantes conseguiam empregos no mercado formal de trabalho. Então, sem renda ou com pouca renda, não conseguiam instalar-se adequadamente nas cidades. A RMSP, em muito pouco tempo, foi tomada por favelas e por loteamentos clandestinos, distantes das regiões centrais.

O crescimento rápido da região, somado ao não planejamento do processo de urbanização, acabou criando problemas de difícil solução. Os loteamentos clandestinos que, inclusive, invadiram áreas de proteção de mananciais e as favelas, dificultarame ainda dificultam o acesso das populações aos serviços urbanos.

Cabe lembrar aqui que não são apenas os mais carentes que enfrentam problemas. $\mathrm{O}$ crescimento desordenado das cidades, acrescido de uma visão inadequada das questões ambientais por conta dos planejadores urbanos, acabou estendendo os problemas para toda a população. Desmatamentos das matas ciliares dos córregos, estreitamento e canalização dos seus leitos, quando somados ao processo de impermeabilização das vias públicas e à excessiva aglomeração de construções, têm causado frequentes enchentes, apesar do grande volume de investimentos para sanar a situação. As enchentes, os congestionamentos rotineiros e a poluição do ar afetam a todos.

Os problemas ambientais da RMSP, sem nenhuma dúvida, decorrem da urbanização: uso inadequado dos recursos naturais, com destaque para a água; habitações inadequadas, como favelas e cortiços; redes de esgotos insuficientes; esgotos não tratados; despejos de resíduos urbanos em áreas públicas; áreas verdes insuficientes; impermeabilização excessiva do solo; confinamento dos rios; coleta e tratamento de resíduos sólidos inadequados.

Alguns problemas são mais destacados. Aágua, por exemplo, há muito tempo é um grande "nó" para os gestores municipais. ARMSP enfrenta permanentemente duas questões complicadas: a quantidade e a qualidade da água disponível. A bacia do Alto Tietê já não sustenta o consumo da população. Desde o final da década de 1970 a região importa água da bacia do rio Piracicaba (Sistema Cantareira), criando problemas de escassez, durante os meses de estiagem, nos municípios dessa bacia. O que parecia uma solução acabou virando um problema, principalmente para a Região Metropolitana de Campinas - RMC (GALLO, 2000).

A partir dos anos 1970, a RMSP não ficará mais sozinha nas mazelas ambientais. Por conta do fenômeno que ficou conhecido como "interiorização do desenvolvimento", outras regiões de São Paulo se tornaram atrativas às populações pobres de outros estados e do próprio Estado, dos seus municípios das regiões interioranas, que migravam atraídas por empregos industriais. Amecanização da agricultura fazia a sua parte nesse processo.

O que ocorreu na RMSP não serviu de exemplo. $\mathrm{Na} \mathrm{RMC}$, quase toda localizada na bacia do rio Piracicaba, a trajetória foi a mesma, como um filme repetido. A RMC beneficiou-se de alguns projetos federais e estaduais, como a instalação de um polo petroquímico em Paulínia e a melhoria das rodovias estaduais, por exemplo. As prefeituras também contribuíram, doando terras às empresas e concedendo isenção de impostos. O cenário para a expansão urbana foi montado e, de novo, não foram previstos mecanismos para a minimização dos impactos.

Na década de 1970, os municípios da RMC e da bacia do rio Piracicaba cresceram muito acima das médias nacional e estadual. Só para se ter uma dimensão do fenômeno: o município de Sumaré chegou a crescer em uma média de $16 \%$ ao ano. Em termos ambientais e sociais, foi o município mais afetado na região. Neste momento, por exemplo, ele enfrenta uma epidemia de dengue (GALLO, 2000).

Os problemas ambientais mais visíveis na RMC e na bacia do rio Piracicaba também decorrem do processo de urbanização. A monocultura canavieira também contribui. Favelização, rede e tratamento de esgotos insuficientes, despejos de resíduos em áreas públicas, impermeabilização excessiva do solo, entre 
outros, aconteceram como na RMSP. Outra "coincidência": as prefeituras que incentivaram o processo de industrialização não previram mecanismos minimizadores dos impactos da urbanização que o acompanhou.

Mais uma "coincidência": o recurso hídrico na RMC é, de longe, o principal problema para os gestores municipais. A região também enfrenta questões quantitativas e qualitativas emrelação às suas águas. A população cresceu e a água, que era abundante, escasseou-se. Redes de esgoto foram instaladas e não foram construídos sistemas de tratamento. Para agravar a situação, a RMSP capta na bacia do Piracicaba reversão pelo Sistema Cantareira $-30 \mathrm{~m}^{3} / \mathrm{s}$. Nos períodos de estiagem, o racionamento de água é comum em municípios da região. Outro agravante: a disponibilidade de água subterrânea é pequena na $\mathrm{RMC}$, insuficiente ao abastecimento urbano. $\mathrm{O}$ consumo de água para fins industriais, com destaque para a química e a petroquímica, também é alto, complicando a situação (GALLO, 2000).

A situação ambiental em relação aos recursos hídricos ganhou contornos tão difíceis que acabou propiciando o surgimento de um movimento ambientalista de grande porte na bacia do rio Piracicaba e na RMC a partir da década de 1980. Tal movimento desembocou na criação do Consórcio Intermunicipal das Bacias dos Rios Piracicaba e Capivari, que congrega as administrações municipais, empresas usuárias das águas e a sociedade civil organizada. Desde a sua fundação, em 1989, o Consórcio tem atuado na busca de soluções para os problemas dos rios da RMC. É bom destacar aqui que a região teve papel importante na elaboração e na implantação de Lei 7663/91, que criou o Sistema Integrado de Gerenciamento de Recursos Hídricos para o Estado de São Paulo (GALLO, 1995).

A criação do consórcio e a posterior instalação dos Comitês de Bacias, previstos na lei, indicam um caminho: o planejamento descentralizado e participativo é a melhor maneira para enfrentar as questões ambientais. Os problemas de abastecimento de água, de tratamento de efluentes, de destinação de resíduos sólidos, entre outros, são mais bem equacionados quando tratados regionalmente. O Comitê de Bacia é o parlamento ambiental, onde os interesses dos diferentes atores sociais devem ser debatidos e enfrentados.

$O$ crescimento da cidade, a vegetação urbana e uso de plantas pela população: a necessidade de um resgate cultural

Grandes transformações agrícolas e agrárias ocorreram nas décadas de 1960 e 1970 provocando o êxodo das pessoas do campo e acelerando o processo de urbanização (PELICIONI, 1998), com todas as consequências já avaliadas acima, a partir dos casos específicos da RMSP e da RMC. Além dos problemas socioambientais discutidos na primeira parte deste artigo, é necessário observar que, no ambiente urbano, o homem recém-migrado, sem preparo nenhum para a vida nas cidades, foi perdendo a sua identidade, sua cultura, e o espaço rural deixou de ser um lugar importante para a experiência humana, tornando-se apenas uma estratégia para obtenção de rendas (PELICIONI, 1998).

A crescente pressão provocada pela expansão desordenada da área urbana sobre os recursos naturais tem provocado graves problemas socioeconômicos e ambientais, que vão interferir diretamente na sua qualidade de vida, principalmente na periferia das médias e grandes cidades (ALVES et al., 2004). A arborização, por exemplo, foi praticamente esquecida pelo poder público, sendo grande parte das árvores existentes decorrente de plantios voluntários, sem planejamento e acompanhamento técnico adequados. Problemas desse tipo são provenientes da falta de planejamento urbano como um todo e, especificamente, no que se refere à arborização urbana. Um dos prováveis motivos para o não investimento nesse setor deve-se aos altos custos gerados com a poda, pois geralmente elas não são preventivas e sim emergenciais, devido à ausência de planejamento (ROCHA et al., 2004)

Em termos de planejamento urbano, a arborização urbana e as "Áreas verdes" assumem importância 
particular nas cidades, tendo numerosos usos e funções no ambiente, podendo-se notar as diferenças entre as regiões arborizadas e aquelas desprovidas de arborização (SILVA, 1998 citado por HARDER et al., 2006). Os locais arborizados geralmente se apresentam mais agradáveis aos sentidos humanos.

Segundo Sanchotene (1994), a presença de arbustos e árvores no ambiente urbano propicia a melhora do microclima através da diminuição da amplitude térmica, como também fornece sombra para os pedestres e veículos, reduzindo a poluição sonora, auxiliando na melhoria da qualidade do ar, servindo de abrigo para pássaros e contribuindo para a saúde física e mental do ser humano na cidade.

Segundo Nucci (2001), citado por Harder et al. (2006), quando se discute sobre a vegetação urbana não se pode esquecer o índice de áreas verdes, pois muitas cidades procuram aumentar seus índices considerando a projeção das copas das árvores sobre as calçadas - e todo espaço não construído - como área verde, sendo que Demattê (1997) não considera essa prática correta, pois o termo "Áreas verdes" é empregado aos diversos tipos de espaços urbanos que têm em comum o fato de serem abertos, acessíveis; relacionados com saúde e recreação ativa e passiva, proporcionando interação das atividades humanas com o ambiente. Entretanto, LLardent (1982), citado por Harder et al. (2006), considera áreas, zonas, espaços ou equipamentos verdes como espaços livres onde predominam áreas plantadas de vegetação, correspondendo, em geral, ao que se conhece como parques, jardins ou praças.

Diante da marcha da urbanização, verificamos que a flora nativa vem sendo dizimada, assim como vários elementos da cultura popular que a acompanham, pois desde o início da civilização o homem faz uso das plantas pela necessidade de sobrevivência, levando-o à descoberta, inclusive, de possíveis aplicações terapêuticas de determinadas espécies (RIBEIRO, 1996). Todo esse crescimento urbano tem provocado uma crescente aculturação e torna fundamental a necessidade de resgatar o conhecimento que a população detém sobre o uso de recursos naturais, entre eles as plantas.

A transmissão oral do conhecimento sobre o uso de plantas é realizada há gerações. Porém, o processo de aculturação, em que as novas gerações buscam os meios modernos de comunicação, causam a perda desta tão valiosa prática. Outro fator que se soma a esta perda cultural é a destruição do habitat natural em que estão inseridas essas sociedades (BRITO e BRITO, 1999 citado por MEDEIROS et al., 2004).

O povo e o local onde se iniciou a tradição de usar plantas como remédios ainda são desconhecidos, mas segundo Mors (1982) e Di Stasi (1996), ao longo de toda história da humanidade, a busca pela cura era considerada uma arte e esta atravessou numerosas fases. No entanto, essas fases não se sucederam com separações nítidas e até hoje, na era dos antibióticos e do grande avanço tecnológico, ainda se encontra, com considerável frequência, o recurso das rezas associado como uso das plantas para expulsar enfermidades, como nas "primitivas" práticas xamanísticas. No processo da evolução da arte de curar, coube aos alquimistas, por exemplo, um passo de grande importância, pois, ao avalizarem determinadas "crendices", em muitos casos, confirmaram acertos da sabedoria popular.

Conforme Di Stasi (1996), o uso de plantas medicinais está associado à evolução antropológica, desde a época em que o ser humano era um simples nômade até se tornar uma espécie sedentária. Com a fixação de moradia surgiram as mais variadas necessidades de sobrevivência. O uso das plantas como forma de tratamento para as mais diversas doenças que comprometiam a saúde das pessoas, através de tentativas de acertos e erros, permitiu curar algumas enfermidades, possibilitando, através desse conhecimento empírico, melhorar a qualidade de vida.

A arte dos benzedores, curandeiros e xamãs, herdada dos magos e feiticeiros de outrora, pode ser vista atualmente em teste nos laboratórios científicos, que passaram a avaliar experimentalmente a veracidade dessas informações, tendo em vista a descoberta de novos medicamentos com base justamente nos conhecimentos que foram adquiridos durante milhares de anos e repassados, de geração em geração, por 
aqueles que são ancestrais da ciência moderna (DI STASI, 1996).

No Brasil, mesmo antes do descobrimento, os índios já faziam uso das plantas não somente para curar: utilizavam-nas para sua subsistência e esses conhecimentos eram passados de geração em geração (LORENZI e MATOS, 2002). Na filosofia indígena, de acordo Lelong (1978), a planta é considerada como fonte de ensinamento, pois, segundo suas crenças, é a planta que promove a cura, ou seja, é responsável pela cura por conta da presença de um espírito inteligente que atua sobre a enfermidade. $\mathrm{O}$ que o índio chamava de espírito inteligente, hoje, graças aos estudos botânicos e farmacológicos, é considerado como o princípio ativo produzido pelos vegetais (DI STASI, 1996).

Coma colonização do Brasil, a utilização das plantas não acontecia apenas na cultura indígena, mas também nas culturas africana e europeia (LORENZI e MATOS, 2002). De acordo com os relatos de Lorenzi e Matos (2002), os europeus, ao chegaram ao Brasil, depararam-se com grande quantidade de plantas usadas pelos indígenas como remédio.

Através dos pajés, os conhecimentos sobre as ervas locais e sobre seus usos eram transmitidos e aprimorados de geração a geração. Tais conhecimentos foram assimilados pelos europeus, principalmente aqueles que se embrenharam no sertão na captura de índios ou na busca de pedras preciosas. Anecessidade de sobrevivência e o contato direto com os índios terminaram por ampliar o conhecimento sobre a flora medicinal brasileira. Esses novos conhecimentos acabaram fundindo-se com os do velho mundo.

Os escravos africanos também deram sua contribuição com as plantas trazidas da África, muitas delas utilizadas em rituais religiosos e também para tratamento de saúde, pelas suas propriedades farmacológicas empiricamente descobertas (LORENZI e MATOS, 2002).

Também os jesuítas e os primeiros colonizadores do Brasil trouxeram da Europa algumas receitas para a cura de doenças. Essas influências deixaram marcas profundas nas diferentes áreas de nossa cultura, sob aspecto material e espiritual, constituindo a base da medicina popular (RODRIGUES e CARVALHO, 2001).

Com o desenvolvimento das cidades e a concentração populacional, é notório que as diferentes visões de seus habitantes acentuem as contradições sociais, provocando uma ruptura com os costumes e tradições locais, o que é amplamente visível no caso do uso das plantas com fins terapêuticos, por exemplo.

Além da perda das raízes culturais, as cidades degradaram-se do ponto de vista da sociabilidade, a partir do crescimento exagerado e desorganizado. Nas grandes cidades, atualmente, as praças, por exemplo, deixaram de ser local de lazer, descanso e até de encontro, onde outrora as pessoas trocavam seus conhecimentos. As ruas foram ocupadas por automóveis, ônibus, impossibilitando as crianças brincar como nas gerações passadas. Nas calçadas, não encontramos mais os moradores sentados em suas cadeiras conversando, mas, no lugar disso, as pessoas passaram a temer assaltos, agressões e vandalismos.

O desenvolvimento urbano acabou gerando problemas ambientais e sociais e a resposta para a superação dessa crise está no desenvolvimento sustentável, pois os modelos de desenvolvimento econômico adotados no Brasil ao longo da sua história têm provocado fortes concentrações de renda e riqueza, criando a exclusão de expressivos segmentos sociais, produzindo a maioria dos problemas que o país enfrenta hoje.

Ao mesmo tempo em que degradam o homem, sua qualidade de vida e seu estado de saúde, esses padrões de desenvolvimento vêm favorecendo a degradação ambiental por meio da exploração predatória de recursos naturais e da poluição, que, por sua vez, têm gerado impactos negativos nas condições de saúde e qualidade de vida da população (MINISTÉRIO DA SAÚDE, 1995).

Considerando o aspecto ético, não é mais aceitável que o desenvolvimento econômico destrua a natureza, esgotando os seus recursos e poluindo os espaços naturais e também os construídos, sem pensar nas gerações futuras. Ao contrário, exige-se cada vez mais 
uma sociedade sustentável, que atenda as suas necessidades sociais, inclusive a dos excluídos, os incluindo com igualdade e justiça, e que preserve, solidariamente, para as gerações futuras os recursos naturais necessários ao seu bem-estar.

Atualmente, com o crescimento urbano e a degradação das áreas naturais, o homem volta a procurar as áreas naturais, ambientes arborizados e com paisagem mais agradável para viver, morar e frequentar.

Para exemplificar uma situação de restrição de áreas verdes e perda de contato com a natureza, tanto do ponto de vista físico como cultural, cita-se o estudo realizado por Telarolli (1993) no município de Araraquara (SP), cuja vegetação ficou restrita ao número reduzido de praças e ruas arborizadas, como sucedidas também na RMSP e RMC e em várias outras regiões do Brasil, visto que a cidade também teve um crescimento rápido e desordenado, fruto do fenômeno migratório relativamente recente.

O trabalho que será relatado a seguir teve como finalidade realizar o levantamento florístico da Praça da Independência e verificar a relação dos frequentadores com a vegetação no município de Araraquara-SP, objetivando compreender, a partir dele, a necessidade de um resgate cultural relacionado à vegetação, ao patrimônio natural regional.

A Praça da Independência foi a primeira criada como jardim e a segunda do município, fundada em 1/ 1/1899, com o nome de Jardim Público. Desde a fundação ela apresenta as mesmas características, exceto pela ausência do prédio em que ficavam os banheiros e do canteiro central, onde havia um coreto e um chafariz (PAPPA et al., 2008).

\section{Procedimentos metodológicos}

O município de Araraquara está no centro do Estado de São Paulo e suas coordenadas geográficas são $21^{\circ}$ 47'37" Latitude Sul e 48 10'52" Longitude oeste de Greenwich. Apresenta área territorial de $1.312 \mathrm{Km}^{2}$, sendo 73,37 $\mathrm{Km}^{2}$ de área urbana. Tem população de 189.634 habitantes (IBGE, 2000). O clima é tropical de altitude, com temperatura média anual de $22^{\circ} \mathrm{C}$.
Floresta Latifoliada Tropical e trechos de Cerrado lato sensu predominam como cobertura vegetal. Com o avanço da monocultura (café, laranja e cana-de-açúcar) houve excessivo desmatamento, restando poucas matas nativas (ARARAQUARA, 2010).

A metodologiautilizada para a investigação da cobertura vegetal existente na Praça da Independência foi uma adaptação do "levantamento rápido - LR" para amostragem da vegetação arbórea de Cerrado, preconizada por Walter e Guarino (2006). Essa técnica visa coletar dados qualitativos de forma expedita, cujos princípios são similares ao método do "caminhamento" descrito por Filgueiras et al. (1994) e Ratter et al. (2000; 2001; 2003), cujo método está baseado em levantamentos designados "wide patrolling" ("varredura"). Basicamente, o LR consiste da realização de pelo menos três caminhadas em linha reta na vegetação, verificando as espécies que vão sendo visualizadas.

O levantamento florístico ocorreu entre março a dezembro de 2009, e consistiu na coleta de material botânico das espécies arbustivo-arbóreas e herbáceas em caminhadas nas trilhas (ruas) existentes na área e nos fragmentos delimitados pelas ruas. As plantas conhecidas que se encontravam com flores ou frutos foram cadastradas durante as visitas na área, e apenas coletados fragmentos das espécies desconhecidas, ou de identificação duvidosa, para compará-los com a bibliografia (LORENZI, 1992; LORENZI, 1998; LORENZI, 2001; LORENZI, H. et al., 2001; SOUZA ELORENZI, 2005) e identificá-los através de uma chave interativa de identificação "on-line" (DEPARTAMENTO DE BOTÂNICA IB/UNICAMP).

As entrevistas foram realizadas aleatoriamente com moradores que residem próximos à praça e seguiram um roteiro com perguntas semiestruturadas, procurando identificar os seus conhecimentos sobre as plantas que existiam na praça e também sobre a sua construção.

\section{Resultados E Discussões}

No levantamento florístico foram identificadas 85 espécies, pertencentes a 69 gêneros e 38 famílias, sendo 3 famílias pertencentes à Gimnospermae e 33 à 
Angiospermae, das quais 31 espécies, em 25 gêneros e 18 famílias são de origem nativa do Brasil e 50 espécies, em 44 gêneros e 27 famílias, de origemexótica. Dentre as Gimnospermae encontradas - 3 espécies , todas são de origem exótica (Cyca circinalis - África e Ásia -, Cupressus funebris - China - e Pinus sp Europa, Ásia e América Norte) e se apresentam como plantas de porte arbóreo, exceto Pinus sp, que está em fase inicial de desenvolvimento.

As plantas exóticas constituem a maior porção da composição florística da praça $(68,23 \%)$, e apenas a estrutura arbórea apresenta número maior de espécies nativas (23). No entanto, as herbáceas e as arbustivas são todas exóticas (39). Isso reflete a pouca prática do uso de plantas nativas no paisagismo e composição de jardins (ver Tabela 2).

Tabela 2 - Comparação da porcentagem de espécies conforme os estratos formados de acordo com o porte - Praça da Independência.

\begin{tabular}{|l|r|r|r|r|r|r|r|r|}
\hline \multirow{2}{*}{ Porte das plantas } & \multicolumn{2}{|c|}{ Nativas } & \multicolumn{2}{c|}{ Exótica s } & \multicolumn{2}{c|}{ S/Identificação } & \multicolumn{2}{c|}{ Total } \\
\cline { 2 - 10 } & \multicolumn{1}{|c|}{$\mathbf{N}^{\circ}$} & \multicolumn{1}{c|}{$\%$} & \multicolumn{1}{c|}{$\mathbf{N}^{\circ}$} & \multicolumn{1}{c|}{$\%$} & $\mathbf{N}^{\circ}$ & \multicolumn{1}{c|}{} & \multicolumn{1}{c|}{$\mathbf{N}^{\circ}$} & \multicolumn{1}{c|}{} \\
\hline Arbóreo & 23 & 27,06 & 19 & 22,35 & 2 & 2,35 & $\mathbf{4 4}$ & $\mathbf{5 1 , 7 6}$ \\
\hline Arbustiva & 0 & 0,00 & 11 & 12,94 & 1 & 1,18 & $\mathbf{1 2}$ & $\mathbf{1 4 , 1 2}$ \\
\hline Herbáceas & 1 & 1,18 & 28 & 32,94 & 0 & 0,00 & $\mathbf{2 9}$ & $\mathbf{3 4 , 1 2}$ \\
\hline \multicolumn{1}{|c|}{ Total } & $\mathbf{2 4}$ & $\mathbf{2 8 , 2 4}$ & $\mathbf{5 8}$ & $\mathbf{6 8 , 2 3}$ & $\mathbf{3}$ & $\mathbf{3 , 5 3}$ & $\mathbf{8 5}$ & $\mathbf{1 0 0 , 0 0}$ \\
\hline
\end{tabular}

Fonte: Dados de pesquisa.

Com relação à estrutura florística da praça, pode-se observar que a estrutura arbórea éformada por espécies nativas como ipês-roxos (Tabebuia avellanedae), canelinhas (Ocotea odorifera e Ocotea corymbosa), cacaus-selvagens (Pachira aquatica), paus-alecrins (Holocalyx balansae), pitanga (Eugenia uniflora), seriguela (Spondias mombin), falsos-babaçus (Attalea oleifera), buris (Allagoptera campestris) e patioba (Syagrus botryophora). As arbóreas exóticas são representadas por tipuanas (Tipuana tipu), flamboyants (Delonix regia), falsa-murta (Murraya paniculata), acerola (Malpighia glabra), jamboamarelo (Syzyium jambos), oitis (Licamia tomentosa), alfeneiro-chinês (Ligustrum lucidum), resedás (Lagerstroemia indica), areca-bambu (Dypsis lutescens) e palmeira-de-leque (Livistona $\mathrm{sp}$ ).

Dentre as arbustivas, a dominância maior ficou para o coqueiro-de-vênus (Dracaena fragrans), costelade-adão (Monstera deliciosa) e iuca-elefante (Yucca elephantipes), que são espécies exóticas, não ocorrendo nenhuma nativa.

Quanto às herbáceas, somente verificamos a presença de uma espécie nativa, a maranta-cinza (Ctenanthe setosa) e exóticas como, moreias (Dietes iridioides), jiboias-verde (Epipremnum pimmtum) e singônio (Singonium angustatum).

Segundo Pappa et al. (2008), a Praça da Independência apresenta as mesmas formas e componentes, exceto pela ausência dos sanitários, os quais só foram construídos em 1916. Aárea verde é formada por $3.850 \mathrm{~m}^{2}$ e não há registros de quais foram as plantas utilizadas inicialmente para compor o jardim durante a fase de construção e ajardinamento, apenas algumas fotografias arquivadas na biblioteca municipal ou na prefeitura da cidade.

De acordo com Telarolli (1993), durante a reforma da praça em 1977, houve, segundo jornais da época, a derrubada de algumas tipuanas octogenárias e canelinhas, sendo estas substituídas por alfeneirojaponês (Ligustrum japonicum). Porém, Pappa et al. (2008), ao realizarem o levantamento histórico e florístico, constataram que essa espécie é o alfeneirochinês (Ligustrum lucidum), e que ainda permanece perto da calçada. 
Pappa et al. (2008) observaram ainda, em documentação de 1928, a presença de palmeirasimperiais (Roystonea sp) e do baguaçu ou falsobabaçú (Attalea oleifera). Entretanto, essas palmeiras já não fazem parte da vegetação atual, restando apenas os babaçus plantados juntos às murtas e paus-brasis (Caesalpinia echinata).

Com a intenção de verificar a ligação dos frequentadores da Praça Independência com a vegetação, foram entrevistadas 42 pessoas - a maioria não conhece os nomes populares das árvores que estão plantadas, desconhece quais são exóticas ou nativas, não tem ciência de que existem plantas frutíferas ou ameaçadas de extinção, como o pau-brasil, e somente consideram a sombra agradável que elas fazem nos bancos ou nos corredores.

A maioria dos entrevistados freqeenta a praça para realizar caminhadas ou para encurtar o caminho até a área do comércio. Dificilmente ficam sentados nos bancos conversando ou fazendo atividades de leitura. A praça deixou de ser um elo com a vegetação e passou a ser apenas um local de lazer, quando muito.

Gomes (2005) considera que as praças são locais da convivência em comunidade e do cotidiano urbano, precisando ser priorizada na cidade para que assuma não somente o papel de área de lazer, mas, sobretudo, de área verde, contribuindo dessa forma como um aparelho importantíssimo na regulação do clima urbano. Nesse sentido, a presença da vegetação, principalmente pela arborização de espaços públicos, como as praças, tornam tais espaços mais atraentes e mais adequados à realização do lazer, especialmente nos horários diurnos. A paisagem urbana fica enriquecida pela estética dos espaços livres públicos.

A praça perdeu, ao longo dos anos, seu poder de ser informativa, mas manteve seu poder aglutinador, conforme relata Casé (2000) citado por Gomes (2005), mas continua sendo, por excelência, um importante espaço livre e público, comum a toda a sociedade, podendo servir como local de lazer e de área verde, mas ela deixou de ser um local de ligação com vegetação nativa da região.

De acordo com Sader (1992), a "Educação
Ambiental poderá contribuir para o processo de transformação da sociedade atual em uma sociedade sustentável, centrado no exercício responsável da cidadania, que considere a natureza como um bem comum, leve em conta a capacidade de regeneração dos recursos materiais, promova a distribuição equitativa da riqueza gerada e favoreça condições dignas de vida para as gerações atuais e futuras".

Uma alternativa para tentar melhorar esse contato com o ambiente natural seria a introdução de trabalhos de Educação Ambiental como, por exemplo, as trilhas interpretativas. A trilha interpretativa constitui-se em um roteiro previamente estabelecido em um sítio natural e/ou artificial, passando por pontos de interesse que podem estar devidamente sinalizados por placas explicativas ou que sejam acompanhados de explicação por parte de um intérprete (CEPA, 2001). A estratégia busca despertar nas pessoas uma relação de intimidade com o meio, proporcionando novas sensações e experiências através do contato direto com este. As trilhas interpretativas do meio ambiente têm sido muito difundidas como instrumento de educação ambiental, especialmente em áreas preservadas, tais como as unidades de conservação, que buscam aliar ao lazer de seus visitantes uma prática educativa.

\section{Considerações finais}

De todo o exposto no texto, que tratou dos impactos socioambientais do crescimento desordenado das cidades e apontou para um provável e possivelmente pernicioso desenraizamento cultural dos migrantes rurais, é possível tirar alguns apontamentos prévios, que poderão servir como balizas para a prevenção dos impactos ambientais, sociais e também culturais do crescimento econômico e urbano:

1) O planejamento econômico não pode acontecer descolado dos planejamentos ambiental e social;

2) $\mathrm{O}$ crescimento das cidades em função do crescimento da economia não pode dar-se ao acaso, não pode ser simplesmente deixado por conta dos mecanismos do mercado;

3) O planejamento urbano deve adotar elementos de prevenção, direcionando a ocupação e o uso do 
solo, de modo a minimizar os impactos sobre os recursos naturais, como água e solo agrícola, por exemplo;

4) Ao se planejar o crescimento da cidade, a partir do crescimento econômico, tem-se que levar em consideração a capacidade de suporte do meio ambiente, avaliando as suas potencialidades e fragilidades;

5) O crescimento da cidade não pode significar uma ruptura cultural, levando a população à perda de memórias, com destaque para as ligadas às questões da natureza;

6) A arborização das ruas e a criação de parques devem fazer, permanentemente, parte das preocupações do planejamento da cidade;

7) Processos democráticos e permanentes de educação ambiental, a partir do poder local, podem contribuir para a preservação das culturas que garantem o equilíbrio da natureza e o uso dos recursos naturais para o bem-estar social;

8) A interação entre a sociedade civil e o setor público pode contribuir para a realização do bem-estar socioambiental;

9) Além da construção de praças e criação de parques, há que se pensar no resgate cultural relativo à vegetação regional; trilhas interpretativas e intervenções simples, como a identificação das espécies (nome popular, científico e origem), podem ajudar no intento resumidamente, ações de Educação Ambiental;

10) Resumindo: hoje, os planejamentos econômico, ambiental e social não podem acontecer isolados e, sobretudo, devem acontecer dentro de um modelo que privilegie a participação da comunidade, o modelo "democrático e participativo".

Quanto ao desenraizamento cultural dos migrantes rurais e seus diversos impactos sobre o meio urbano e sobre as condições de vida nas cidades, a questão é um tanto mais complexa e merece uma avaliação mais detalhada que, a princípio, não coube no pequeno espaço deste artigo, merecendo um espaço mais específico, que cuide mais acuradamente e com mais vagar desta importante questão. O presente texto debruçou-se mais firmemente sobre um aspecto importante do desenraizamento cultural, a ignorância sobre as plantas com as quais os atuais cidadãos urbanos convivem diuturnamente.

\section{REFERÊNCIAS}

ALVES, J.B; SOUTO, J.S.; SILVA, W.A.; LOPES, L.I.; RODRIGUES, C.R.F. Diagnóstico ambiental de ruas e bairros da cidade de Teixeira, PB. R. Árvore, Viçosa-MG, v.28, n.5, p.755-764, 2004.

BRITO, A. R. M. \& BRITO, A. A. S. Medicinal plant research in Brazil: data from regional and national meetings. In: M.J. Balick; E. Elisabetsky \& S.A. Laird (eds.). Medicinal resources of the tropical forest - biodiversity and its importance to human health. Columbia University Press, New York, p. 386-401, 1999 citado por DEMATTÊ, M.E.S.P. Princípios de paisagismo. Jaboticabal: Funep, 104p., 1997.

CASÉ, Paulo. A Cidade Desvendada. Rio de Janeiro: Ediouro, 2000. 180p.

\section{CENTRO DE ESTUDOS E PESQUISAS} AMBIENTAIS - CEPA. Trilhas de interpretação da natureza. Poços de Caldas: ALCOA, 2001.

\section{COMISSÃO MUNDIAL SOBRE MEIO}

AMBIENTE E DESENVOLVIMENTO

(CMMAD). Nosso futuro comum. Rio de Janeiro:

Editora da Fundação Getúlio Vargas, 430p, 1991.

DI STASI, C. L. et al. Plantas medicinais, arte e ciência: um guia de estudo interdisciplinar. Projeto Edição de textos de Docentes e Pósgraduação e pesquisa da UNEP (PROPP). São Paulo: Editora da Universidade Estadual Paulista, 230p., 1996.

FERREIRA, Yoshiya Nakagawara. Metrópole sustentável?: não é uma questão urbana. São Paulo Perspec., São Paulo, v. 14, n. 4, 2000. 
Disponível em: http://www.scielo.br, Acesso em: 27 Jun 2008.

FILGUEIRAS, T.S.; NOGUEIRA, P.E.; BROCHADO, A.L. \& GUALA II, G.F.

Caminhamento: um método expedito para levantamentos florísticos qualitativos. Cadernos de Geociências 12: 39-43. 1994.

GALLO, Z. A defesa da qualidade das águas da Bacia do rio Piracicaba: o papel da CETESB e de todos nós. Tese (doutorado). Campinas, SP: IG/ UNICAMP, 227p., 2000.

A proteção das águas, um compromisso do presente com o futuro: o caso da bacia do rio Piracicaba. Dissertação (mestrado). Campinas, SP: IG/UNICAMP, 1995. 151p.

Gomes, M. A. S. As praças de Ribeirão PretoSP: uma contribuição geográfica ao planejamento e à gestão dos espaços públicos. Uberlândia, 204p., 2005.

HARDER, I. C. F.; RIBEIRO, R.C.S.; TAVARES, A.R. Índices de Área Verde e Cobertura Vegetal para as Praças do município de Vinhedo, SP. R. Árvore, Viçosa-MG, v.30, n.2, p.277-282, 2006.

LLARDENT, L. R. A. Zonas verdes y espaços livres en la ciudad. Madrid: Closas Orcoyen, 538 p., 1982.

LELONG, B. Arte de viver e filosofia das sociedades amazônicas. (En Marge L occident dt se utres, abri presénce et pensée). Paris, p. 41-58, 1978.

LORENZI, H. Árvores brasileiras: manual de identificação e cultivo de plantas arbóreas nativas do Brasil. Nova Odessa: Plantarum, v. 1. 532 p., 2008.
LORENZI, H. Árvores Brasileiras - manual de identificação e cultivo de plantas arbóreas brasileiras. 2 ed. Nova Odessa: Plantarum, v. 2, 2001.

LORENZI, H. Plantas Daninhas do Brasil: terrestres, aquáticas, parasitas e tóxicas. Nova Odessa: Plantarum. 640p. 2008.

LORENZI, H. Manual de identificação e controle de plantas daninhas. Nova Odessa: Plantarum. 339p. 2006.

LORENZI, H.; MATOS, F.J.A. Plantas medicinais no Brasil: nativas e exóticas. Nova Odessa: Plantarum. 339p. 2008.

LORENZI, H.; SOUZA, H.M. de; TORRES, M. A. V.; BACHER,L.B. Árvores exóticas no Brasil: madeiras, ornamentais e aromáticas. Nova Odessa: Plantarum, 367 p., 2003.

LORENZI, H.; COSTA, T. M.; CERQUEIRA, L. S. C. de; FERREIRA, E. Palmeiras brasileiras e exóticas e cultivadas. Nova Odessa: Plantarum, 416 p., 2004.

MEDEIROS, T. F. M., FONSECA, S. V.; ANDREATA, P. H. R. Plantas Medicinais e seus usos pelos sitiantes da Reserva Rio das Pedras, Mangaratiba, RJ, Brasil. Acta Botânica Brasileira, São Paulo, v.18, n.2, abril/junho, 2004.

MINISTÉRIO DA SAÚDE. Plano nacional de saúde e ambiente no desenvolvimento sustentável diretrizes para implantação. Brasília, DF, 1995.

MORS, W. Plantas Medicinais. Ciência Hoje; v.3, p. 14-19, 1982.

NUCCI, J. C. Qualidade ambiental e adensamento urbano: umestudo de ecologia e planejamento da paisagem aplicado ao distrito de Santa Cecília (MSP). 
São Paulo: USP, FFLCH, 236 p., 2001.

PAPA, D.M.A.; RESTAINO, E.; SOSSAE, F.C., GERALDO, J. Abordagem Histórica e Florística da Praça da Independência No Município de Araraquara - SP. Fórum Ambiental da Alta

Paulista. vol. IV, p. 120 - 139. 2008.

PELICIONI, M. C. F.. Educação ambiental, qualidade de vida e sustentabilidade. Saude Soc., vol.7, no.2, p.19-31, 1998.

RATTER, J.A.;BRIDGEWATER, S.; RIBEIRO, J.F.; DIAS, T.A.B. \& SILVA, M.R.. Estudo preliminar da distribuição das espécies lenhosas da fitofisionomia cerrado sentido restrito nos estados compreendidos pelo bioma Cerrado. Boletim do Herbário Ezechias Paulo Heringer. 5: 5-43. 2000.

ROCHA, R.T.; LELES, P. S. S.; OLIVEIRA, S.N.NETO. Arborização de vias públicas em Nova Iguaçu, RJ: o caso dos Bairros Rancho Novo e Centro. R. Árvore, Viçosa-MG, v.28, n.4, p.599607, 2004.

RODRIGUES, G. E. V.; CARVALHO, A. D. Plantas medicinais no domínio dos cerrados. 1. ed. Lavras, MG; UFLA, Editora UFLA;180p. 2001.

SADER, E. A ecologia será política ou não será. In: GOLDENBERG, M. org. Ecologia, ciência e política: participação social interesses em jogo e luta de idéias no movimento ecológico. Rio de Janeiro,
Revan, p. 135-42, 1992.

SANCHOTENE, M. C. C. Desenvolvimento e perspectivas da arborização urbana no Brasil. In: CONGRESSO BRASILEIRO DE ARBORIZAÇÃO URBANA, 2, 1994, São Luís. Anais... São Luís: Sociedade Brasileira de Arborização Urbana, p. 15-26, 1994.

SILVA FILHO, D. F.; PIZETTA, P. U. C.; ALMEIDA, J.B.A. Banco de Dados Relacional para Cadastro, Avaliação e Manejo da Arborização em Vias Públicas. R. Árvore, Viçosa-MG, v.26, n.5, p.629-642, 2002.

SIRKIS, A. O desafio ecológico das cidades. In: TRIGUEIRO (coord.). Meio ambiente no século XXI: 21 especialistas falam da questão ambiental nas suas áreas de conhecimento. Campinas, SP: Armazém do Ipê (Autores Associados), 367p. 2005.

TELAROLLI, R. Memória Urbana de Araraquara - Panorama da cidade na passagem do século; A história do Jardim Público: da inauguração (1899) até a imperiosa necessidade de uma remodelação. Jornal O Imparcial.

Edição Comemorativa. Araraquara Domingo 22/ 08/1993. Araraquara-SP.

WALTER, B.M.T. \& GUARINO, E.S.G. Comparação do método de parcelas com o "levantamento rápido" para amostragem da vegetação arbórea do Cerrado sentido estrito. Acta Botânica Brasilica. 20: 285-297. 2006.

RECEBIDO EM 17/10/2010

ACEITO EM 1/12/2010 